\title{
NOTAS SOBRE A PRESENÇA DE FERNANDO PESSOA NO BRASIL
}

\author{
Alfeu Sparemberger ${ }^{1}$
}

\section{Resumo}

Este artigo de revisão traz à consideração, inicialmente, as principais perspectivas de abordagem da obra de Fernando Pessoa, de acordo com a leitura de Eduardo Lourenço. Na sequência apresenta e analisa a trajetória da obra pessoana no Brasil, estabelecendo as linhas básicas da recepção do poeta português. O período considerado estende-se do início do século 20 até o final da década de 40 . Para tanto, o texto incorpora as primeiras apreciações críticas da obra de Fernando Pessoa produzidas por críticos portugueses e transcritas em periódicos brasileiros e as primeiras incursões de brasileiros na multifacetada produção do poeta luso. O nome de Fernando Pessoa nunca foi completamente desconhecido no Brasil, mesmo sendo autor de uma obra dispersa em revistas de efêmera duração.

Palavras-chave: Recepção. Fortuna crítica. Fernando Pessoa.

\begin{abstract}
This article review brings initially into consideration, the main approach perspectives of the work of Fernando Pessoa, according to the reading of Eduardo Lourenço. The paper also presents and analyzes the history of Fernando Pessoa's work in Brazil, establishing the basic outlines of the Portuguese poet's reception. The period under consideration for this work, extends from the early $20^{\text {th }}$ century until the late 40's. To this purpose, the text incorporates major critical assessments of Fernando Pessoa's work from Portuguese critics, the ones transcribed in Brazilian newspapers and journals, and the first Brazilian incursions into the multifaceted work of the Portuguese Poet. The name Fernando Pessoa has never been completely unknown in Brazil, even being an author of a work scattered in newspapers and journals of ephemeral duration.
\end{abstract}

Keywords: Reception. Critical Fortune.. Fernando Pessoa.

\section{A trajetória da fortuna crítica de Fernando Pessoa}

No ensaio “A fortuna crítica de Pessoa” (1985/86), Eduardo Lourenço assinala que a obra de Fernando Pessoa, desconhecido do grande público quando de sua morte, em 1935, não passou despercebida por seus pares. O construto textual pessoano começa a ser erigido em um número especial da revista Presença, como um primeiro índice de reconhecimento da expressiva dimensão cultural que sua obra alcançaria. A jovem geração presencista é a

\footnotetext{
${ }^{1}$ Centro de Letras e Comunicação - Universidade Federal de Pelotas - UFPel - e-mail alfeu.sparemberger@terra.com.br
} 
responsável pelo primeiro olhar crítico lançado sobre a produção de Fernando Pessoa, constituindo-se, assim, num dos mais sólidos esteios da fortuna crítica do autor da "Ode Marítima”. No início dos anos 50 a obra de Pessoa alcança pleno reconhecimento. Nessa trajetória a compreensão do fenômeno heteronímico impôs-se como tema crítico merecedor de investigação. Eduardo Lourenço realiza um sucinto panorama acerca da fortuna literária de Pessoa, indicando as obras que colaboraram para a conformação daquele construto e transformaram a sua obra no eixo central da cultura portuguesa. O livro de Jacinto do Prado Coelho - Diversidade e unidade em Fernando Pessoa (1949) - representa o momento em que a obra do autor de Mensagem (1935) (recorde-se que este foi o único livro em língua portuguesa publicado em vida por Pessoa) torna-se "referência clássica dos estudos universitários", cumprindo um "rito de passagem da marginalidade cultural para o reconhecimento institucional”. A partir deste marco Pessoa passa a ser visto como um “clássico contemporâneo” e é traduzido e estudado em vários países. No Brasil, em especial, a obra pessoana conheceu notória expansão e repercussão. No final dos anos 60 a "estrelaPessoa” já é visível no conjunto da cultura ocidental. A “consagração mítica” é consequência do célebre ensaio de Roman Jakobson (escrito em colaboração com Luciana S. Picchio e denominado “Les Oxymores Dialectiques de Fernando Pessoa”, 1968), que insere Fernando Pessoa na constelação responsável pela Modernidade, rivalizando com Joyce, Picasso, Stravinsky. Eduardo Lourenço conclui este tópico panorâmico da fortuna crítica de Pessoa indicando cinco perspectivas adotadas pela crítica relativamente à sua obra.

A tese de Eduardo Lourenço é a de que a fortuna pessoana conheceu um percurso relativamente estruturado. Nesse processo é revelador, mais do que uma cronologia, o rol das mudanças de ótica em relação à obra de Pessoa e à “própria realidade literária.” No contexto português a mudança de aportes teóricos e críticos operou-se, em boa medida, por causa de Pessoa.

A primeira perspectiva inscreve-se numa “ordem classicamente literária”, “encarnada” pelos presencistas e "sua estética de essência romântica”. A obra de Pessoa apresenta problemas insolúveis aos presencistas, centrados que estavam na "tríade eu, espontaneidade, originalidade, núcleo desta poética”. Nessa ótica, para Eduardo Lourenço,

A percepção e o juízo da poesia pessoana estão subdeterminadas pela questão que durante uma vintena de anos fará correr muita tinta "psicologista: a da sinceridade ou da insenceridade da criação de Pessoa. [...] Não tendo compreendido ou aceitado que o gênio de Pessoa estava ligado precisamente à contestação radical da única poética válida a seus olhos, esta primeira geração crítica, a que está na base da sua promoção literária - em termos clássicos - não o ‘compreende’ ou compreende-o demais, mas não nos termos adequados à ruptura exigida pelo tipo de criação do 
autor de 'Ode Marítima’. Pretende-se confiar Pessoa nos limites de um 'literário’ que a sua obra está precisamente em via de subverter (1985/86, p. 24).

A segunda orientação pretendeu ver a literatura como "reflexo ou espelho do real”, ou, por extensão, como transfiguradora do real concebido como realidade social, tributária de uma visão da "História como luta de classes". A poesia de Pessoa, ou antes seu construto discursivo, afasta-se ostensivamente "do que nós podemos conferir à aventura humana enquanto esforço bem sucedido para racionalizar o seu destino concreto, social” (LOURENÇO, 1985/86, p. 24). A “resistência” da obra de Pessoa ao esforço de um vínculo racional ao dado concreto decorre da compreensão de sua poesia como "fuga” para "fora do mundo”, na expressão de Eduardo Lourenço e, ainda, da exigência ideológica com que o marxismo configurou a exegese das obras literárias por volta de década de 40 do século 20 por todo o ocidente. A despeito de leituras penetrantes, o veio ideológico dominante naquela época acaba deportando o poético para uma “instância heterogênea”.

A terceira perspectiva considera a obra de Fernando Pessoa “um universo constituído”. Trata-se agora da resolução do "enigma visível da Heteronímia, reconduzindo-o ao da conciliação entre a diversidade evidente e a unidade profunda”. O acento desta perspectiva desloca a investigação do significado para o significante, vincando a viagem pelas vias da “matéria do seu imaginário - a própria língua” - como resolução de uma poesia plural na sua matriz.

O “caso Pessoa” não deriva, pelo viés da quarta perspectiva, somente da literatura, alcançando, a rigor, a inauguração de uma "literatura-outra”, exigindo uma “crítica-outra”. O registro nesta linha investigativa é outro:

Trata-se, ao mesmo tempo, de uma aventura existencial e ontológica, através da qual se joga não só o sentido do Eu, mas, também, o sentido do Sentido. É a relação verbo-mundo, signo-realidade que é questionado mesmo se o seu suporte continua sendo ainda uma pluralidade de sujeitos (LOURENÇO, 1985/86, p. 25).

É uma linha que pretende organizar as demais perspectivas, aderindo ao poeta, sem a recorrência a "uma crítica heterogênea", admitindo-se a revelação de uma "poesiaconhecimento”. A apreensão da obra pessoana decorre de um “ato sem mais significação que a autorizada pela vivência de sua poesia, o que, no caso de Pessoa, quer dizer poesia que põe em causa a essência mesma da poesia, e, nela, a própria literatura” (LOURENÇO, 1985/86, p. 25) e, a rigor, a “experiência do poético nem releva da aventura ontológica”. Nesse viés, 
Teríamos de pensar num continente novo, numa perspectiva na qual a visão paradoxal da Ausência importa mais que a do Ser, em suma, qualquer coisa da ordem do neo-ontológico, quer dizer, no tipo de intuições que encontraram nas formas mais extremas do neoplatonismo [...] (LOURENÇO, 1985/86, p. 25).

O ser assim compreendido ultrapassa o plasma da linguagem ou é a visão de "uma linguagem que não consegue falar”. Daí que a crítica é, por mimetismo, metacrítica, “jogo de espelhos” que é, afinal, nas palavras de Eduardo Lourenço, “um jogo no limite do silêncio”.

A última perspectiva analisa a obra de Pessoa como um jogo do "vivido imaginário”, como "poeto-drama”. Em conformidade com uma alteração do empreendimento crítico, ocorre o deslocamento "para o imaginário da língua, para os seus labirintos e impasses, cena atrás da qual nada se joga, salvo o próprio jogo” (LOURENÇO, 1985/86, p. 25). O eu não tem outro conteúdo que não o efeito das palavras - fato que a acuidade de Pessoa tão bem capturou -, pois o eu é condensado num efeito puramente linguístico. As vertentes de uma tal consideração da obra pessoana - como objeto e simulacro - remetem a R. Barthes e J. Lacan. Tais perspectivas, ao revelarem Fernando Pessoa, converteram-no num “mito cultural vivo”, fenômeno ainda em contínua expansão. Nesta linha, José-Augusto Seabra e Leyla Perrone Moisés conferiram a este gênero de leitura o seu diploma universitário de nobreza.

\section{Fernando Pessoa no Brasil: primeiros registros}

Quando, mais para o fim dos anos 60, a obra de Fernando Pessoa experimentava significativa visibilidade na cultura ocidental, ela já conhecia também um histórico representativo de leituras no Brasil. A extraordinária voga de Pessoa no Brasil, para além da assimilação que a poesia do autor de Mensagem destina à pátria como lugar de uma língua comum, deveu-se sobretudo aos estudos críticos e de divulgação de Gilberto de Melo Kujawski, Fernando Segolin, Massaud Moisés, Leodegário de Azevedo Filho, Carlos Filipe Moisés, Maria Lúcia dal Farra, José Basílio Quesado e Wilma Areas, além dos portugueses Fernando Mendonça e João Alves das Neves. Eduardo Lourenço completa a lista:

Se destacarmos entre essas contribuições, como particularmente importantes pela antecipação e originalidade, as de Cleonice Berardinelli, Benedito Nunes e Leyla Perrone, teremos uma idéia da extensão e da qualidade da contribuição brasileira para a fortuna crítica de Pessoa (LOURENÇO, 1985/86, p. 23).

A “divulgação pública” de Fernando Pessoa no Brasil deu-se em 1938, no Boletim de Ariel, com um artigo assinado por Adolfo Casais Monteiro intitulado "O exemplo de Fernando Pessoa”, transcrito do Diário de Lisboa (de 9 de dezembro de 1937). Outros 
números do mesmo Boletim, segundo Arnaldo Saraiva, prosseguiram com a divulgação de Pessoa no Brasil:

\begin{abstract}
O n. 11, de agosto, publicava também uma nota que dava Pessoa como o "único poeta português igualável a Camões” e transcrevia poemas que em abril tinham aparecido na revista lisboeta Mensagem. E o n. 12, de setembro, voltava a incluir poemas pessoanos, desta vez transcritos da Revista de Portugal. Também a Revista do Brasil publicou em novembro de 1938 um artigo, "A apresentação de Fernando Pessoa”, assinado por João Gaspar Simões (SARAIVA, 2004, p. 187).
\end{abstract}

Nessa “Apresentação” João Gaspar Simões, que na época trabalhava nos papéis deixados pelo autor da Ode Triunfal, oferece ao leitor brasileiro um apreciável quadro informativo sobre a obra de Fernando Pessoa. Em linhas gerais, é possível destacar uma exegese que contempla, na primeira parte, aspectos como:

a) o nome de Fernando Pessoa começa a frequentar os círculos que abordam a poesia portuguesa, divulgando a obra de alguém quase “desconhecido em vida”;

b) a dispersão da obra de Pessoa em publicações efêmeras, dificultando um conhecimento a pleno e imediato do autor (a necessidade que tem o interessado em recorrer a revistas da época);

c) o equívoco em chamar Pessoa de poeta futurista ("conquanto tivesse experimentado a chamada esthetica futurista”); Pessoa aderiu a todas as revoluções estéticas e ainda criou uma “escola literária”: o sensacionismo;

d) o contexto e os companheiros, como Almada Negreiros e Mário de Sá-Carneiro, dispostos a "quebrar o rythmo morto das letras nacionaes";

e) o fingimento e a concepção da arte como um drama (Fernando Pessoa era "um drama em gente”); os heterônimos e a mistificação; afirma João Gaspar Simões: "Fernando Pessoa só era mystificador para o não ser. Era a necessidade de se esconder a si próprio que o levava a mystificar. Mas era mystificando que Pessoa se realizava como artista. Quer dizer: mystificando, cumpria-se. Mystificando: realizava-se na sua própria mystificação. 'Fingir é conhecer-se' - escreveu elle. Porque fingia, Fernando Pessoa conhecia-se. A sua arte era a única maneira de Fernando Pessoa se conhecer a si próprio” (1938, p. 449).

E da segunda parte do texto é possível destacar:

a) a referência a uma "taboa biobliographica” enviada por Fernando Pessoa à revista Presença (de 1928), em que o autor da Mensagem apresenta e “explica” o fenômeno da heteronímia, com referências sobre dados biográficos de todas as criações e a lista das obras de cada uma delas; 
b) a retomada do tópico da mistificação; nos termos de Gaspar Simões: "Isto é: o problema da realidades daquellas personalidades fictícias punha-o Fernando Pessoa como problema metaphysico: o problema do conhecimento da realidade. A sua mystificação assumia assim categoria de problema philosophico. E a verdade é haver tanta mystificação na attitude de Fernando Pessoa como na do dramaturgo ou na do romancista. Pois não é certo que mystificam o dramaturgo e o romancista, creando personagens de quem nos descrevem os actos e a figura?” (1938, p. 451).

Na terceira parte encontra-se:

a) o fenômeno da heteronímia é explicado como tendência orgânica de Pessoa para a “despersonalização e para a simulação”;

b) uma explicação de Gaspar Simões: “O seu drama em gente é um arranjo ou uma mystificação pela qual lhe foi permitido falar em nome de varias tendências da sua personalidade sem nunca descer àquelle nivel da realidade a que só descem os que crêem no real: os dramaturgos e os romancistas” (1938, p. 452).

A quarta parte desta “Apresentação de Fernando Pessoa” investe ainda em alguns aspectos tais como:

a) no fenômeno da heteronímia (pois considera o fato de que a vida de Pessoa permaneceu no anonimato e o poeta mantinha uma relação de indiferença para com o mundo circundante); assim, "Fernando continuava a representar o seu drama”; "Falava de Alvaro de Campos com a mesma convicção alheada com que Balzac referia aos seus heróes. Mas os heróes de Fernando Pessoa não se realizavam literariamente. Viviam a seu lado, naquella sombra cheia de mysterio que era para elle a realidade da sua própria imaginação” (SIMÕES, 1938, p. 452);

b) na formação escolar de Fernando Pessoa, em parte realizada em "contexto" britânico; o lugar da infância e a inteligência como principal matriz da realização poética: “A poesia, para um poeta intellectual como Fernando Pessoa, era, é mais uma decantação de valores gerados na própria intelligencia do que um aflorar de emoções. Um homem mais intelligente que sensível não sabe ser original sem o amparo da intelligencia. É a intelligencia que lhe nobilita estheticamente a expressão. [...] Assim, quando Fernando Pessoa fala do amor, não se refere a nenhum amor concreto e particular: o amor nos versos de Fernando Pessoa é um pensamento feito poesia” (SIMÕES, 1938, p. 454).

E, finalmente, nos dois últimos blocos do texto, Gaspar Simões destaca: 
a) a inteligência como predisposição para a poesia: "Em Fernando Pessoa a intelligencia era um instrumento de communicação com as potencias secretas da própria vida” (SIMÕES, 1938, p. 456);

b) o interesse de Fernando Pessoa pela astrologia: "Mas também não era uma intelligencia especulativa-racional. Não: era uma intelligencia determinada pelas forças latentes de uma imaginação que se procurava nos próprios astros” (SIMÕES, 1938, p. 456);

c) o ocultismo (no caso, poemas ocultistas antes como textos simbolistas): "Mas não se pode dizer que Fernando Pessoa fosse uma sensibilidade inteiramente dada a essa espécie de desagregação total da personalidade no seio do Universo, que é até certo ponto a característica de toda a poesia occultista. Fernando Pessoa nunca perdia a consciência da opposição entre o seu eu e o mundo. A sua consciência não se fundia com a consciência universal. Pessoa sabia distinguir com firmeza o Eu do não Eu. A sua intelligencia não o deixava perder o controle das suas faculdades” (SIMÕES, 1938, p. 456-457);

d) a importância de um poema como a “Ode Marítima” na obra de Pessoa, capaz de ilustrar o próprio drama pessoano.

O nome de Fernando Pessoa, contudo, não era, àquela altura, desconhecido no Brasil. Apareceu inicialmente na transcrição do conto “O homem dos sonhos”, de Mário de SáCarneiro, publicado pela Gazeta de Notícias (RIO, 1913), dedicado ao escritor português. Por volta do mesmo ano Carlos Maul mencionou o nome de Pessoa numa conferência; na Biblioteca Internacional de Obras Célebres, antologia de literatura internacional, editada em Portugal, mas dirigida especialmente ao Brasil, Fernando Pessoa “deixou várias traduções assinadas, e outras anônimas, feitas do inglês e do castelhano”; Ronald de Carvalho, com intermediação de Luís de Montalvor, travou contato com Fernando Pessoa; e, finalmente, cabe destacar o “capítulo” acerca da participação de brasileiros na revista Orpheu, porta-voz dos anseios de vanguarda em Portugal. Ademais, “não custa acreditar que, em conversa com camaradas brasileiros, esses escritores portugueses [Veiga Simões, Álvaro Pinto, Jaime Cortesão, Carlos Lobo de Oliveira, Antônio Ferro e José Osório de Oliveira], amigos de Pessoa, o citassem como um dos melhores representantes da literatura que então se escrevia em Portugal; e só é estranho que alguns deles, como Álvaro Pinto e Antônio Ferro, que o liam - dispersamente, é verdade - desde 1912, pelo menos, nada tenham feito publicamente para o divulgar no Brasil” (SARAIVA, 2004, p. 187). 
Entre os brasileiros, o primeiro a mencionar a grandeza de Fernando Pessoa foi Ribeiro Couto. Em sua passagem por Portugal, em 1929, é possível que este autor tenha conhecido pessoalmente Fernando Pessoa. Ele registrou o conhecimento da obra de Pessoa em carta dirigida a Carlos Drummond de Andrade, em 1931. Antes, porém, de apresentar o primeiro registro público sobre a obra de Pessoa no Brasil, cabe assinalar que Mário de Andrade, contemplado por Carlos de Queirós com a oferta da Homenagem a Fernando Pessoa (de 1936), era já conhecedor da obra do poeta português. No seu texto "Uma suave rudeza” (de 1939), da obra O empalhador de passarinho, Mário de Andrade aponta para o risco de se escrever sobre “arte estrangeira”, porque uma literatura não é uma procissão de indivíduos desconexos entre si e da realidade nacional, e escreve estas palavras sobre o autor de "Ode Marítima":

O caso de Fernando Pessoa, para esta crônica portuguesa, me parece característico
do que afirmo. Os poucos brasileiros meus amigos, mais ou menos versados nessa
notável inteligência portuguesa, se assombram um bocado com a genialidade que lhe
atribuem certos grupos intelectuais de Portugal. Ora, nem portugueses nem
brasileiros estaremos provàvelmente errados nisto. É que Fernando Pessoa
representa, em certos grupos portugueses, uma concretização de ideais múltiplos que
nos escapa. E desconfio que à infinita maioria dos portugueses o nosso Machado de
Assis estará na mesma posição (ANDRADE apud SCHUTEL, 1976, p. 84)

A publicação do texto de Adolfo Casais Monteiro, em 1938, mostra que a recepção brasileira coincide com a interpretação dos poetas e críticos da revista Presença, naquela primeira perspectiva lançada por Eduardo Lourenço. Nas palavras de Monteiro, a obra de Fernando Pessoa "surge sem esses mil e um traços de humanidade que costumam surgir da leitura das tentativas pelas quaes o artista se foi aproximando da perfeição, do amadurecimento” (1938, p. 215). A obra de Pessoa "surgiu definitiva”, “sem evolução”. A simultaneidade dos heterônimos garantiu à obra de Pessoa a síntese de uma evolução não realizada no tempo, por meio de fases de hesitação e de procura. Adolfo Monteiro argumenta que, para Pessoa, a vida era a obra, a primeira confundindo-se com a de milhões de indivíduos. A segunda, produzida sem qualquer traço de uma existência particular, desenhava em eternidade a fisionomia do poeta, sem que o tempo atuasse no apagamento dos sinais da passagem do homem. Tal fato, porém, não “desumaniza” a obra pessoana, ao contrário, pois ela foi diretamente ao “interior do homem”. E acrescenta Adolfo Casais Monteiro: “O que lhe falta é interesse pelo occasional, pelo circumnstancial, que muitos julgam ser todo o humano, ai delles! A obra de Fernando Pessoa não revela o eterno do homem no accidental, mas no proprio eterno. Despreza os disfarces do que parece: vae direita ao ser” (ANDRADE apud SCHUTEL, 1976, p. 215). 
Na sequência do texto, revelando uma intimidade resultante da convivência pessoal com Fernando Pessoa, Adolfo Casais Monteiro deixa entrever um tema caro ao grupo presencista: a pureza de um ideal, vale dizer, a sinceridade do artista, de obrigatória inscrição na obra poética. O homem Pessoa não está na obra, ou melhor, a vida de Fernando Pessoa, como já referido anteriormente, era a obra, de um ideal ascético, em que mais transparece o homem - no seu contato com os outros homens - do que a obra. Daí, talvez, a irrealidade da existência de alguém chamado Fernando Pessoa:

\begin{abstract}
Ele era, para a maior parte de nós, tanto de outro mundo que não foi precisa a sua morte para nos apparecer na pura nudez de sua obra, despido do tempo. Procurou sempre existir nella; dahi o que á nossa fraqueza de demasiado terrenos pode-se afigurar-se duro e incomprehensivel sacrifício: essa vida obscura que levou, ser porventura o mais perfeito signal da sua grandeza. Lembremo-nos da indifferença e do silencio, quando não do riso soez e do sarcasmo, que pouco ou mais os seus contemporâneos lhe deram em paga da obra, compenetremo-nos bem do que significa de domínio o soberbo, o heróico isolamento em que viveu, e poderemos então dar o seu inteiro valor á fé inquebrantável com que permaneceu fiel a si próprio e ao seu destino, que era levar a cabo a sua obra (MONTEIRO, 1938, p. 215).
\end{abstract}

\title{
3 A consolidação da presença de Fernando Pessoa no Brasil: a década de 40
}

No início dos anos 40, como oportunamente lembra João Alves das Neves, Domingos Carvalho da Silva, em artigos pouco referidos, abordou a obra de Fernando Pessoa. O primeiro, “Através da nova poesia portuguesa” (Correio Paulistano, 19 de setembro de 1943), destacava Fernando Pessoa como “talvez o mais notável expoente da nova poesia portuguesa” (apud NEVES, 1992, p. 56). Um segundo artigo, “Fernando Pessoa - ele mesmo”, publicado no mesmo Correio Paulistano (06/02/1944), comentava a antologia publicada por Adolfo Casais Monteiro em Lisboa, em 1942, e mencionava ainda um terceiro artigo, publicado no mesmo periódico paulista. Os dados confirmam um crescente interesse no Brasil pela obra do autor da Mensagem, fato consignado ainda pelo artigo de Murilo Mendes, “Fernando Pessoa”, publicado na Folha da Manhã (RECIFE, 10/12/1944). O artigo de Murilo Mendes, além de revelar dados biográficos do poeta português, reconhecido como "extraordinário", de esclarecer como estabeleceu contato com a obra e elogiar o trabalho de João Gaspar Simões, organizador das edições da obra de Pessoa, investe na exegese da produção pessoana quando afirma: "Este é o poeta da falta de solução, poeta da falta de atrito com as coisas, poeta da solidão essencial, sem ornatos. Até agora os dois grandes poetas da solidão em Portugal eram Antero de Quental e António Nobre. Mas penso que Fernando Pessoa é ainda muito mais isolado” (apud FONSECA, 1985, p. 106). Ao explicar a afirmação, acrescenta: “Quanto a 
Fernando Pessoa, está sozinho mesmo. Só com o só. Com a Esfinge, que não é outro senão ele próprio”. E finaliza, observando que Fernando Pessoa

\begin{abstract}
Possui (se se pode aplicar este verbo a um homem que não possui coisa alguma) o exacto conhecimento da inutilidade dos gestos humanos. Sua angústia não gesticula, não emprega a retórica. É de uma lucidez implacável. Chegou ao mais minucioso exame de si mesmo, à filtragem da sua própria personalidade, a que se refere, apesar de tudo, com carinho, como se se tratasse de uma terceira pessoa. Extremamente complexo, tocou a própria simplicidade. Repito: não conheço lucidez tão grande em nenhum outro poeta. Mas não é um racionalista (FONSECA, 1985, p. 107).
\end{abstract}

Murilo Mendes cita vários poemas de Fernando Pessoa, destacando o lado místico e esotérico da obra, revelando especial interesse pela “Ode Marcial”. Ressalta-se que, 20 anos depois, Mendes voltou a se ocupar de Fernando Pessoa, “desta vez para repudiá-lo”, no seu texto “Murilograma a Fernando Pessoa” (de 1964). A identificação de Murilo com Fernando Pessoa reaparece na década de 70, por meio de um retrato-colagem, descrição poética de "um encontro imaginário” com o autor da “Ode Triunfal”. Esse trabalho representa, como assinala Francis Lopes da Silva, a atividade de um "Murilo leitor crítico, contemplativo, a reverenciar escritores e artistas representativos da cultura clássica, cujas obras lhe eram bastante familiares, graças às constantes pesquisas e ao apurado gosto estético do poeta” (2008, p. 88).

Lúcio Cardoso também foi atraído pela poesia de Fernando Pessoa, com predileção pelas Poesias, de Álvaro de Campos. Assinala João Alves das Neves que "O texto de Lúcio Cardoso é na verdade um curto ensaio e havia sido lido anteriormente (24/5/1946) durante um encontro na Faculdade de Direito de Belo Horizonte. O entusiasmo de Lúcio Cardoso ia desde a Mensagem à Ode Marítima, obra daquele que 'mais se aproximou de Camões, o único que pode ser colocado à sua grande sombra'. E lembrava que 'certamente todo poeta é um ser múltiplo', mas em Fernando Pessoa a multiplicidade era 'a própria essência do seu ser, a condições do seu drama, os alicerces da sua genial criação’ (NEVES, 1992, p. 58). Lúcio Cardoso defendeu a tese de que "na diversidade da obra pessoana existe uma unidade essencial” (apud FONSECA, 1985, p. 109). O texto de Lúcio Cardoso é precursor, em certa medida, da postulação da unidade na diversidade da obra pessoana: "Não são cinco ou seis homens diferentes, como ele próprio procurou nos fazer acreditar, baptizando-os com nomes diversos. Ricardo Reis, Alberto Caeiro, Álvaro de Campos e Bernardo Soares são faces do mesmo homem - Fernando Pessoa é o outro, simplesmente” (FONSECA, 1985, p. 109). Ainda como registro, recorda João A. das Neves que, "Felizmente, o grande escritor mineiro reincidiu e em 10/12/1950 veio a público na mesma carioca A Manhã dar 'Uma explicação’ 
de Fernando Pessoa, além de ter comentado o "Mar português”, em Letras Brasileiras (Rio de Janeiro, em janeiro de 1950)” (FONSECA, 1985, p. 59).

No presente quadro de recepção da obra de Fernando Pessoa merece considerável relevância a publicação da antologia Poetas Novos de Portugal (1944), organizada e prefaciada por Cecília Meireles. Escrito, provavelmente, em 1943, o prefácio era impactante, pois afirmava, sem rodeios, que Fernando Pessoa era o "caso mais extraordinário das letras portuguesas”. Naquela ocasião constituía um dos mais importantes estudos no Brasil sobre a poesia portuguesa dos “novos” autores. Cecília Meireles menciona e transcreve, inicialmente, trecho de uma carta de Fernando Pessoa, dirigida a João Gaspar Simões, em 1931, em que ele “explica” o fenômeno da heteronímia. Descortinando ao leitor brasileiro o fenômeno da heteronímia, Cecília recorre a dados de uma outra Carta de Fernando Pessoa, esta de janeiro de 1935, novamente direcionada para o esclarecimento da multiplicidade de assinaturas do poeta luso. Assim, são apresentados Ricardo Reis, Alberto Caeiro e Álvaro de Campos. Cecília Meireles arremata a apresentação dos heterônimos nos seguintes termos

\footnotetext{
Os que de mais perto viram e acompanharam a vida desse singular poeta parece não terem concluído com absoluta clareza sobre o que ele tentou explicar minuciosamente a respeito de seus heterónimos. Ficou-lhes a dúvida sobre os limites de independência que haveria alcançado cada uma dessas outras personalidades inventadas ou recebidas (NEVES, 1992, p. 70).
}

Apresentado ao leitor brasileiro o fenômeno da heteronímia, Cecília Meireles aborda a obra do ortônimo, explicando não se tratar de "um caso simples: lírico da mais clara essência, é, ao mesmo tempo esotérico, e súbito se faz profético e patriótico” (NEVES, p. 70). Assinala que Fernando Pessoa não chegou a concretizar os projetos expostos na carta a Adolfo Casais Monteiro, destacando que a "sua obra mais valiosa acha-se inédita e dispersa em revistas", vindo a público somente o livro Mensagem, em 1934. Cecília transcreve as respostas de Fernando Pessoa aos reparos feitos por Gaspar Simões quanto ao reduzido número de publicações levado a cabo por ele, Pessoa. Como resposta, o autor da "Ode Triunfal” relembra as circunstâncias da publicação, um concurso literário, em que Mensagem recebeu o segundo prêmio, e entende “que foi a melhor estreia que eu poderia fazer”. De fato, a faceta nacionalista, mística e sebastianista da obra de Pessoa não havia sido plenamente manifesta nas colaborações remetidas às revistas, exceto o poema "Mar português", que faz parte da Mensagem. Cecília Meireles assim comenta a atitude de Fernando Pessoa: 
naquele momento possua algum sentido profético que os tempos venham a demonstrar, mas que, só com míseros olhos profanos, não se consegue atingir com precisão (NEVES, 1992, p. 71).

Cecília Meireles selecionou poemas do livro Mensagem e dos heterônimos Ricardo Reis, Álvaro de Campos e Alberto Caeiro, numa amostragem significativa. A maioria dos poemas ainda não havia sido publicada em livro, somente em revistas, confirmando que Cecília tinha um sólido conhecimento das publicações do Modernismo português. E, de fato, é conhecida sua viagem a Portugal em 1934, na companhia do marido português Correia Dias, para proferir conferências nas Universidades de Coimbra e Lisboa. Restou frustrada, no entanto, a tentativa de conhecer Fernando Pessoa. A crítica literária tem, de outra parte, apontado para afinidades entre as obras de Fernando Pessoa e Cecília Meireles: todas de ordem existencial, vocabular e estilística.

A presença “oficial” de Fernando Pessoa no Brasil pode ser explicada como decorrente do início da publicação, pela Editora Ática, em Lisboa, a partir de 1942, das obras completas do poeta. É resultado ainda da publicação, também em 1942, de uma Antologia de Autores Portugueses e Estrangeiros (em dois volumes) por Adolfo Casais Monteiro. Já residente no Brasil, Monteiro organizou, para a Coleção Nossos Clássicos, uma antologia da lírica pessoana, publicada em 1957, incluindo poemas em inglês, representada por quatro dos 35 Sonnets, apresentados no original e em tradução do próprio Casais e de Jorge de Sena. De certo modo, essa antologia constituirá, para o leitor brasileiro, o texto “canônico” da poesia de Fernando Pessoa. Como já referido, porém, os poetas brasileiros já tinham ciência da produção divulgada antes dessas antologias: conheciam as edições da Ática e também as revistas do Modernismo português, afora o conhecimento do livro Mensagem. Aliás, a revista Orpheu, em seu primeiro número, foi um projeto luso-brasileiro, provavelmente idealizado no Brasil. Encerra-se aqui o estudo do percurso da obra de Fernando Pessoa em terras brasileiras nesse período. Cabe em outro capítulo a expansão da presença de Pessoa no Brasil nos anos 60 e 70.

\section{Considerações finais}

A riqueza da obra pessoana como um marco inesgotável da literatura moderna - em linhas como a alteridade e a identidade, características das manifestações poéticas do século 20, - está na matriz da multiplicidade e da variedade de abordagens críticas que mereceu nos últimos anos. Assim, pode-se afirmar com garantia que a obra do autor de Mensagem 
constitui objeto de praticamente todas as orientações teóricas e críticas (tanto do texto quanto do social). As metodologias utilizadas, a partir daquelas fontes, produziram leituras de ordem sociológica, política, ocultista, psicanalítica, biográfica, estilística, filosófica etc.

O rastreamento da recepção crítica da obra de Fernando Pessoa no Brasil revela, em grande medida, os desdobramentos do aporte da Teoria Literária no país. A obra do escritor português foi objeto de estudo de poetas, jornalistas, da crítica não especializada e conheceu uma respeitável repercussão nos meios acadêmicos, consolidada a partir dos anos 60 do século passado, desde, com segurança, da publicação do primeiro volume da coleção Nossos Clássicos (Livraria Agir), em 1957, inaugurada por Fernando Pessoa. O estudo da recepção literária possibilita retraçar o destino dos textos pessoanos no imaginário dos leitores brasileiros.

\section{Referências}

FONSECA, Edson Nery da. “Três poetas brasileiros apaixonados por Fernando Pessoa” Colóquio - Letras, . Lisboa, n. 88, 1985. p. 102-109.

LOURENÇO, Eduardo. “A fortuna crítica de Pessoa”. Revista Comunidades de Língua Portuguesa, São Paulo, n. 6/7, 1985/86. p. 18-27.

MONTEIRO, Adolfo Casais. “O exemplo de Fernando Pessoa”. Boletim de Ariel, n. 7, 1938. p. 215.

NEVES, João Alves das. As relações literárias de Portugal com o Brasil. Lisboa: Instituto de Cultura e Língua Portuguesa, 1992. (Biblioteca Breve).

SARAIVA, Arnaldo. Modernismo brasileiro e modernismo português : subsídios para o seu estudo e para a história das suas relações. Campinas, SP: Editora da UNICAMP, 2004 [1986].

SCHUTEL, Luísa Enóe Cabral. Mário de Andrade: ensaios e textos comentados sobre autores contemporâneos brasileiros e portugueses. Rio de Janeiro: Educom, 1976.

SILVA, Francis Paulina Lopes da. “Pessoa e Murilo Mendes: contrapassantes”. Verbo de Minas - Letras, Juiz de Fora, v. 7, n. 14, jul-dez., 2008. p. 87-96.

SIMÕES, João Gaspar. “Apresentação de Fernando Pessoa”. Revista do Brasil, ano 1, n. 5, nov., 1938. p. 448-460. 